\title{
Letters
}

Website: www.bmj.com

Email: letters@bmj.com

\section{The aftermath of the Bristol case}

Case arose through a failure of action, not of detection

EDITOR-Smith refers to "key protagonists overreacting" in his editorial on the Bristol case. ${ }^{1} \mathrm{He}$ joins "even the strongest supporters of the Labour government" in bemoaning "its excessive concern with media opinion." Yet he tells us (and, from his privileged platform, the world) that this case is a "once in a lifetime drama..., Shakespearean in its scale and structure," which will have the result that "the trust that patients place in their doctors...will never be the same again."

This is a strange stance for the editor of a scientific journal committed to encouraging rational ideas in medicine. Dramas like this (even dramas that occur more often than once in a lifetime) are certainly "powerful levers for change." But that is not a reason for senior medical journals to seize on them and use them to promote pre-existing agendas of change that have only a tangential bearing.

The lesson of the Bristol tragedy, when the dust and the shouting outside the General Medical Council have subsided, is that there was an inexcusable failure of existing mechanisms of control. The tragedy provides no rational support for the wholesale imposition of systems of monitoring

Advice to authors
We prefer to receive all responses electronically,
sent either directly to our website or to the
editorial office as email or on a disk. Processing
your letter will be delayed unless it arrives in an
electronic form.
We are now posting all direct submissions to
our website within 72 hours of receipt and our
intention is to post all other electronic
submissions there as well. All responses will be
eligible for publication in the paper journal.
Responses should be under 400 words and
relate to articles published in the preceding
month. They should include 55 references, in the
Vancouver style, including one to the BMJ article
to which they relate. We welcome illustrations.
Please supply each author's current
appointment and full address, and a phone or
fax number or email address for the
corresponding author. We ask authors to declare
any competing interest.
Letters will be edited and may be shortened.
www.bmj.com
letters@bmj.com

and control on doctors in general. Such systems may or may not be necessary, and the $B M J$ should be arguing that if they are introduced it should be only with proper testing, so that ill effects (which $\mathrm{I}^{2}$ and others have predicted) can be determined and weighed against the benefits predicted by Smith among others. But that has little to do with the Bristol case. Here the problem was not a failure of detection; it was a failure by those in authority to take any action on the warnings that they repeatedly received. What purpose will all the monitoring in the world serve if society cannot respond to the shouts of warning it is already receiving?

I have not found that the level of trust in my practice has "all changed, changed utterly." This is partly due to patients' well known capacity for exempting their own doctors from the strictures they apply to the profession in general. Of course we must look for careful progress, but this is not the time for responsible journals to indulge in emotive polemic.

James A R Willis General practitioner

Alton Health Centre, Alton, Hampshire GU34 2QX

1 Smith R. All changed, changed utterly. BMJ 1998;316: 1917-8. (27 June.)

2 Willis JAR. The paradox of progress. Oxford: Radcliffe Medical, 1995.

Doctors should not have to fail before they are given support

EDITOR-The Bristol case has highlighted the need for a system of detecting and rehabilitating doctors not performing to an acceptable standard. ${ }^{1}$ The General Medical Council's plans for such a system combine, comprehensively, fairness in the process while attempting to secure the safety of the general public. ${ }^{2}$ Finding these doctors is important, but surely we should ask why we have poorly performing doctors at all.

Poor undergraduate or postgraduate training, communication difficulties, and family or personal problems may be the basis for some poor performance, ${ }^{1}$ but many good doctors break under the strain of patient demand in impossible circumstances. In my specialty, general practice, some poorly performing doctors are identified in the leafy suburban practices, but most seem to be from the most deprived parts of Britain, often facing a difficult task in single handed practice. I wonder how many of us might become poorly performing doctors if faced with a consultation rate twice the national average, a daily diet of violent drug addicted patients, and constantly vandalised premises.

Doctors working in these circumstances have a choice. They can try hard-and it is hard-to provide the same service to their patients as doctors in more affluent areas provide; they can do this by cutting their list sizes (and of course their incomes). Alternatively, they can do the minimum, developing a siege mentality to protect themselves from patients demanding services they can't provide. This isn't why they became doctors, and gradually they become demoralised and switch off.

It is a tribute to our profession that most doctors facing such difficulties belong to the former group. My practice population has a rate of chronic illness twice the national average, high standardised mortality ratios, and a high unemployment rate, but we receive no deprivation payments. Since the inception of the NHS no partner in my practice has remained until retirement. Some have paid a high personal price for their devotion to their patients. We are fortunate in being well supported by our nursing and clerical staff, but we can see how easy it is to be overwhelmed by workload.

I support the General Medical Council's work in detecting poorly performing doctors at an early stage, but prevention is better than cure. Why should we allow good doctors to be damaged by permitting the sort of working conditions prevalent in many deprived areas? These doctors should not have to fail before they are given support.

Brian McKinstry General practitioner

Ashgrove Health Centre, Blackburn, West Lothian EH47 7LI

1 Klein R. Competence, professional self regulation, and the public interest. BMJ 1998;316:1740-2. (6 June.)

2 General Medical Council. Performance procedures; a guide to the new arrangements. London: GMC, 1997.

\section{Society of Clinical Psychiatrists supports} doctors who have been suspended

Editor-The Society of Clinical Psychiatrists has data on 171 suspensions of senior hospital doctors. Enough details were obtained on 135 completed cases for us to determine the principle trends. In only 22 were the suspensions proved justified; 110 doctors had been wrongly suspended and either had to be reinstated (58) or retired (52) as part of an expensive settlement; and three doctors died as a direct consequence of the suspension.

Thirty eight suspensions were the result of whistleblowing by colleagues or other 
staff alleging professional incompetence. Ten cases are still outstanding. Fault was proved in only two of the remaining 28 . This was despite the odds being heavily against the accused doctor. The prosecution selects and pays most of the members of the disciplinary panel, and the burden of proof is the balance of probabilities rather than the more rigorous "beyond reasonable doubt."

The motives behind the whistleblowing varied. In some cases the motive was intellectual arrogance, particularly in inbred departments. Some colleagues regard a different style of clinical practice as incompetence. Occasionally the morbidity and mortality of patients of the accusers were marginally higher than those of patients of the accused doctor. Other motives included minority intolerance, professional jealousy, and power struggles over control of a hospital department. Such cases are contrary to the Geneva declaration, the United Nations declaration of human rights, ${ }^{1}$ and the General Medical Council's ethical rules. The suspensions are contrary to European Union law on civil rights. ${ }^{2}$ But it is easy to dress up allegations so that an administrator suspends the doctor first and investigates afterwards.

Suspensions and the accompanying professional isolation are damaging, and clinical reactive depression may result; the rate of suspensions has doubled in the past year. The Society of Clinical Psychiatrists has established an informal service whereby a consultant psychiatrist provides therapeutic care and if necessary a place of sanctuary (outside the NHS, because the accused doctors do not trust patient confidentiality under these circumstances). The society plans to arrange this scheme more formally, involving over 200 consultant psychiatrists. But why should such a service be necessary? The chief executive of the NHS has said that doctors wrongly suspended should receive financial compensation for the harm done despite his claim that suspension is a neutral act. $^{3}$

Chief executives should be aware that whistleblowing may have hidden motives. Donaldson has shown that there is a more humane and less wasteful way of dealing with so called difficult doctors, which does not automatically lead to suspension. ${ }^{4}$

P J Tomlin Honorary secretary

Society Clinical Psychiatrists Study Group,

Downton, Wiltshire SP5 3HJ

1 United Nations. Universal declaration of human rights. BMJ 1997;315:1455-6.

Whistleblowing or character assassination. BMJ 1998;316 1756-7. (6 June.)

3 Langlands A. The suspension of $\mathrm{Dr}$ O'Connell. In Committee of Public Accounts: fortieth report. London: HMSO, 1995:21.

4 Donaldson L. Doctors with problems in an NHS workforce. $B M J$ 1994;308:1277-82.

\section{Benefits of openness and teamwork must} be emphasised

EDITOR-I believe we must not condemn the actions of "bad doctors" as if they are isolated felons who take the responsibility entirely for themselves. Drs Wisheart and Dhasmana and those who chose to ignore the problem were or are part of the establishment ${ }^{1}$-an establishment that indirectly allows problems to go unchecked.

I feel ashamed to be a member of such a profession. The autonomy of the individual seems to be so important that suspicious fellow professionals have to take draconian steps with obvious damaging effects to the whole of the medical profession before something can be done. I would opt for the "less punishment but less crime" option -that is, a climate where small problems can be aired quickly and easily and no one is allowed to be totally isolated and autonomous.

Through initial and continuing medical education, universities and professional bodies should teach professionals the benefits of openness and teamwork. Emphasis should not be put on the ability to cope on one's own without recourse to colleagues. How often have anaesthetists like me had to intervene by sending for a more senior surgeon because the junior surgeon performing the operation thought that he or she would lose face in doing so? In an atmosphere where teamwork was the accepted norm, perhaps Drs Wisheart and Dhasmana would have considered that they could ask for the help and additional training (or careers advice) that they so desperately needed.

So where were the professional bodies of the surgeons and anaesthetists? We who elect their officers may wish to ask where they will be for us. Would we wish them to ignore our minor problems as they grow and speak only when the General Medical Council has pronounced on our case? Of course it is terrible to be falsely accused, especially when there seems to be little difference between absolute denial of the problem and formal proceedings. Discreet inquiries and perhaps an invitation for Drs Wisheart and Dhasmana to go on sabbatical to a centre with higher survival figures (if comparable), long before the problem got out of hand, would have been the best answer for both sinned against and sinners.

Doctors must stop the "I can cope on my own" routine and start a new era of openness.

Rachael Dawson Senior house officer

Department of Anaesthetics, Queen Elizabeth Hospital, King's Lynn PE30 4ET rachael_dawson@mcmail.com

1 Dyer C. Compensation claims expected to follow GMC's findings. $B M J$ 1998;316:1691. (6 June.)

\section{Armed forces need independent civilian} adviser who can be approached in confidence

EDitor-I was interested to read the comments by "the great and the good" on the dilemma of the junior surgeon with an underperforming consultant. ${ }^{1}$ The guidance from the General Medical Council and the Senate of Surgery of Great Britain and Ireland is clear. ${ }^{23}$ In reality, however, whistleblowing may not be an option.

A few years ago I was a junior in the armed forces. One of the consultants had a high complication rate for one procedure, and I was seriously concerned for the safety of his patients. My own consultant was aware of the problem and even joked about it. The consultant outranked me both professionally and militarily. Challenging the conduct of a superior is fraught with danger; as well as jeopardising one's career, one faces a real risk of being charged with insubordination. There was no mechanism by which I could safely express my concerns. Had I done so I am sure that the consequences for me would have been serious.

Had there been an independent civilian adviser who could be approached in complete confidence I would certainly have blown the whistle on this consultant.

1 Five times: coincidence or something more serious? $B M$ 1998;316:1736-40 [with comments by M Irving, D M Berwick, P Rubin, T Treasure]. (6 June.)

2 General Medical Council. Duties of a doctor: good medical practice. London: GMC, 1995

3 The surgeon's duty of care. In: Guidance for surgeons om ethical and legal issues.

Deaths are acceptable in some specialties but not all

EDITOR-Appropriately, we accept a certain failure rate in cardiac surgery. ${ }^{1}$ We generally believe that oncologists have done their best when their patients die. Psychiatrists and mental health teams, however, are put under tremendous pressure to prevent all deaths in their patients and receive blame and censure when their patients die.

A tenth of people with major depression and schizophrenia commit suicide. Do we really believe that all these deaths are avoidable? Many people have struggled bravely with distressing symptoms, a restricted life, and stigma from society over many years before choosing to die. Does major mental illness have a core mortality that cannot be decreased even in the best resourced and best run service? Are we holding people responsible, and even driving them out of their chosen specialty, ${ }^{2}$ for adverse events that they can do little to influence? I suspect so.

Alison J Gray Senior registrar

Herefordshire Community Health NHS Trust St Mary's Hospital, Hereford HR4 7RF

1 Treasure T. Lessons from the Bristol case. BMJ 1998;316: 1685-6. (6 June.)

2 Kendall RE, Pearce A. Consultant psychiatrists who retired prematurely in 1995 and 1996. Psychiatr Bull 1997;21: $741-5$.

Series of operations with low mortality may exhibit high average mortality by chance

EDITOR-Poloniecki showed some of the difficulties that may seriously mislead when perioperative mortality statistics are being interpreted. ${ }^{1} \mathrm{He}$ chose an example from cardiac surgery, a high risk specialty with a national average perioperative mortality of $25 \%$. Those difficulties are much increased and new ones are introduced when mortality in most other surgical specialties is assessed because the average mortality for major elective procedures is usually much 
Estimated sample sizes to show significance of excursions away from average perioperative mortality (number of operations for which excursion is estimated to have $5 \%$ probability of occurring by chance)

\begin{tabular}{lcccc} 
& \multicolumn{4}{c}{$\begin{array}{c}\text { No of operations needed when true } \\
\text { average mortality is: }\end{array}$} \\
\cline { 2 - 5 } $\begin{array}{l}\text { Nature of } \\
\text { excursion }\end{array}$ & $\mathbf{0 . 5 \%}$ & $\mathbf{1 \%}$ & $\mathbf{2 \%}$ & $\mathbf{4 \%}$ \\
\hline $2 \times$ average & 800 & 400 & 200 & 100 \\
\hline $3 \times$ average & 260 & 130 & 65 & 32 \\
\hline
\end{tabular}

Deaths are assumed to occur randomly; if deaths occur in clusters even more operations will be needed in sample.

less that 4\%. In 1988 a colleague and I showed that even large series of operations with a low mortality may exhibit two or three times the average mortality by chance alone (table). ${ }^{2}$

When an individual surgeon's performance of a particular operation is being assessed a series extending over several (or perhaps many) years, beginning at consultant appointment, would be needed if the assessment is not to be distorted merely by chance. If, as Poloniecki suggests, a second assessment period might be required (maybe after a complaint to the General Medical Council) the delay before professional conduct could be properly assessed would be absurdly long. Little seems to have been done to collect any data (complete or even estimated by sampling) on national average mortality for specific major operative procedures except in cardiothoracic surgery.

The public's interest in the performance of individual surgeons is understandable. But for politicians and some health economists to have pretended that an assessment based on a comparison of individual surgeons' crude mortality with national averages will improve the public's confidence in the NHS seems about as sensible as proposing to dispense justice by using the random number generator of the National Lottery.

Roger Hole Retired consultant urologist Wynd House, Hutton Rudby, North Yorkshire TS15 0ES

1 Poloniecki JD. Half of all doctors are below average. BMJ 1998;316:1734-6. (6 June.)

2 Hole R, Haywood JK. Auditing perioperative mortality. Ann R Coll Surg Engl 1988;3:184.

\section{Concept of collective responsibility is important}

EDITOR-In the wake of the General Medical Council's findings on the three doctors in the Bristol case, Klein and the media pose the question whether information regarding the performance of individual consultants should be available to the public. ${ }^{1}$ This is at a time when consultants, particularly cardiothoracic surgeons, feel isolated, vulnerable, and subject to blame. Focusing excessively on individual performance promotes risk averse behaviour throughout the NHS. Risk averse behaviour encompasses views such as "although professionally capable, I am not going to do this because I might be blamed for something." Such risk averse behaviour will lead to barriers within the NHS: doctors versus nurses, doctors versus managers, doctor versus doctor, and ultimately doctor versus patient. Barriers within an organisation allow blame to be shifted away from the many on to a few.

Focusing in isolation on individual consultants' performance is a retrograde step. In contrast, effective communication and collective responsibility are behaviours that remove divisions and optimise the quality of an organisation. The absence of barriers within an organisation engenders a natural openness and confidence in its dealings with its customers. Each patient should have unequivocal information about the results of an organisation (trust or department) as a whole. The availability of institutional or departmental data engenders collective responsibility; the availability of data for an individual does not. If the concept of collective responsibility is acquired by independent professionals (nurses and doctors in the NHS) the organisational disaster that occurred in Bristol will be prevented in the future.

Jim Egan Consultant respiratory physician North West Lung Centre, Wythenshawe Hospital, Manchester M23 9LT

JJGEgan @aol.com

1 Klein R. Competence, professional self regulation, and the public interest. BMJ 1998;316:1740-2. (6 June.)

\section{General Medical Council's disciplinary hearings should be confidential}

EDITOR-The quasi-judicial style of the General Medical Council's disciplinary proceedings, which were much publicised in the long running Bristol case, ${ }^{1}$ seems to have much in common with the procedures followed in the courts. It is therefore a matter of both surprise and concern that, unlike the embargo on press comment for court hearings, the media can indulge in speculative comment before a council's hearing has been completed, the verdict of the disciplinary committee has been announced, and professional misconduct has been established or refuted. The General Medical Council needs to retain the confidence of the profession and the public as it addresses the crucial issue of self regulation for doctors. If the outcomes of its proceedings are to be seen as fair and balanced rather than as trials by the media, this loophole must be closed as a matter of urgency.

The council may have part of the remedy. There does not seem to be a good reason for allowing an interval of over two weeks between the announcement by the council of its findings in the cases brought against the three doctors and the final hearing to decide on their fitness to practise.

Douglas Lee Consultant in transfusion medicine National Blood Service Lancaster, PO Box 111, Royal Lancaster Infirmary, Lancaster LA1 4GT

1 Dyer C. Compensation claims expected to follow GMC's findings. BMJ 1998;316:1691. (6 June)
Returning contracts to regional level might prevent such cases

EDITOR-Much has been written in both the medical and the lay press about the Bristol cases. ${ }^{1}$ Proposals have been made-some sensible, some less so- to ensure that such a situation does not recur. I have seen no mention, however, of what I believe to have been an important contributory factor-the moving of consultant contracts to hospital level as part of the setting up of trusts.

A situation in which clinicians and members of the employing authority work together on a daily basis in a relatively closed community may well lead to problems: the natural tendency of an autonomous organisation is to close ranks when faced with possible adverse publicity. The courage, persistence, and career sacrifice required of a person who is prepared to step out of line in the interest of patients have been clearly shown. ${ }^{2}$

A return to the system in which our contracts were held at a higher level, such as the region, would be a simple and inexpensive measure that would help prevent such situations developing to the point of disaster. The Bristol case is the most publicised such case, and rightly so because of the loss of young lives. But there have been several other places where long and damaging disputes have built up because the case had become "too local" and personalities were too important.

Peter Fisher President

NHS Consultants' Association, Great Bourton,

Banbury, Oxfordshire OX17 1QH

1 Treasure T. Lessons from the Bristol case. BMJ 1998;316: 1685-6. (6 June.)

2 Dyer C. Compensation claims expected to follow GMC's findings. BMJ 1998;316:1691. (6 June.)

\section{Airline pilots are assessed every six} months, so why shouldn't doctors be?

EDITOR-Seeing the television coverage of the angry crowd's reaction to James Wisheart and his discredited surgical colleagues $^{1}$ prompted me to voice my concern about measuring deaths to improve surgery in England. Waiting for a surgeon to kill enough people until, after standardisation for case mix and severity, the death rate of his patients is statistically higher than that of colleagues, is like shutting the stable door after the horse has bolted. At this point many patients would have died and the surgeon's professional reputation and probably whole life would have been irreparably destroyed.

My husband is an airline pilot, one of a group of professionals who are carefully monitored. Every six months he is assessed by a senior training captain in a flight simulator. The simulator test includes a variety of technical and managerial problems. Pilots who fail it have to go through retraining. Those who continue to fail can no longer fly. This system seems appealing to me. After all, it would be ridiculous to monitor the number of passengers whom a single pilot had killed in comparison with his colleagues before action was taken to remedy his flying skills. 
In medicine we need regular assessment of our skills by respected and senior colleagues. Such a system has been started for public health doctors in the West Midlands. The quality of the work we do and the effectiveness and efficiency of the management in our departments are reviewed annually. I for one would rather be told that my professional skills were not suitably in line with modern standards, should this ever be the case, before the population of Shropshire began to die unnecessarily as a result.

I agree with the BMA that self regulation is important ${ }^{2}$ and that our professional skills should be assessed by other doctors in our specialty. If doctors were unable to listen and heed advice during such processes, however, then management would have to act. I cannot believe that an airline would allow pilots to continue flying its passengers if, after assessment by their senior professional colleagues, they were considered unfit to fly.

Rosemary J Geller Director of public health Shropshire Health Authority, Shrewsbury, Shropshire SY3 8XL

Dyer C. Compensation claims expected to follow GMC's findings. BMJ 1998;316:1691. (6 June.)

2 Johnson J. Making self regulation credible. BMJ 1998;316: 1847-8. (20 June.)

\section{Supraregional neonatal cardiac surgery works in Western Australia}

EDITOR-Having read Treasure's editorial about the lessons to be drawn from the Bristol case, ${ }^{1}$ we wish to put the case for supraregional neonatal cardiac surgery despite extreme distances. Western Australia has a population of 1.8 million with an incidence of congenital heart disease of 7.65/1000 live births. A mean of nine infants a year require cardiac surgical intervention with cardiopulmonary bypass in the neonatal period. These infants are transported in commercial aircraft by the Western Australian Neonatal Transport Service from Perth to the Royal Children's Hospital, Melbourne.

The distance between the hospitals is nearly $3000 \mathrm{~km}$, and the trip lasts six hours. The infant travels in a transport incubator with inbuilt ventilator and infusion pumps attached. Monitoring is by electrocardiography and pulse oximetry, with blood pressure and blood gas tensions being measured. The medical escort is a paediatric registrar or consultant or a neonatal intensive care nurse, or both. The infant's parent(s) usually travel on the same flight.

We have recently conducted an audit of 10 years of interstate transports to assess mortality and morbidity. ${ }^{2}$ The largest subgroup in this audit comprised 46 patients with transposition of the great arteries. The first arterial switch operation was performed in Melbourne in 1983. The unit currently performs an average of 30 switch operations each year, in a catchment population of 10 million. Between January 1986 and December 1995, all 46 patients with transposition of the great arteries had the arterial switch operation. Of these patients, seven were ventilated and 17 had prosta- glandin $\mathrm{E}_{1}$ infusions. The one year survival was $100 \%$, and the current cohort survival is $98 \%(45 / 46)$. This compares favourably with quoted rates in Treasure's editorial. The youngest patient in this group is now $2^{1 / 2}$ years old and the oldest 12 . Initial developmental follow up data on 43 of the patients shows a $7 \%$ incidence of important problems, three patients having borderline intellectual function or hemiplegia, or both. Again, such figures compare well with those in other published reports ${ }^{3}$ and show that Western Australians are served well by current management with supraregional transfer.

The financial costs of interstate travel and accommodation for the parents are paid by the state health department. Although the parents of infants who are transported over ultralong distances suffer additional emotional costs, they benefit as a group from the excellent survival rates of their infants.

Katharine Gardiner Senior registrar, department of neonatology

Patrick J Pemberton Head, department of neonatology

Jim Ramsay Head, department of cardiology

Princess Margaret Hospital, PO Box D184, Perth, 6001, Western Australia

patrick.pemberton@health.wa.gov.au

1 Treasure T. Lessons from the Bristol case. BMJ 1998;316: 1685-6. (6 June.)

2 Gardiner KH, Pemberton P, Ramsay JM. Audit of neonata cardiac transport, Perth to Melbourne, 1986 to 1995 . In:

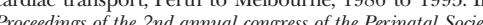
Proceedings of the 2nd annual congress of the Perinatal Societ of Australia and New Zealand; 29 Mar-2 Apr 1998. Alice Springs:

3 Hovels-Gurich HH, Seghave MC, Dabritz S, Messmer BJ, von Bernuth G. Cognitive and motor development in pre-school and school-aged children after neonatal arteria switch operation.J Thorac Cardiovasc Surg 1997;114:578-85.

Techniques for measuring quality of care need to be assessed

EDITOR-I agree that we should be concerned about providing the best quality care possible, and we should do what we can to improve health care. But hard questions should be asked about the planned solutions to the Bristol cases. It is easy to jump on the Bristol bandwagon'; what happened there was wrong, but will the suggested solutions improve health care? And would they have prevented what happened?

It is disturbing that a failed suggestion from the United States-publishing hospital mortality league tables-is the prime consideration. ${ }^{2}$ The concept of a Commission for Health Improvement is likewise noble, but inspecting hospitals every three or four years indicates a role similar to that of the Office for Standards in Education in Britain, which has been criticised for expensive and contradictory outcomes. Attempts in the United States to measure quality of care have foundered, usually because of inability to take account of severity of illness. ${ }^{23}$ When attempts to stratify for disease severity are used, major limitations become apparentfor example, the data collected are amenable to manipulation, are unreliable, or ignore important outcome variables.

I applaud and support any research into how quality should be measured. But it is research and should be subjected to the same rigour as a new medicine is. Is there evidence that quality is measured? Is outcome improved? And, as for any new product, what is the cost? At present, such expensive and time consuming techniques are not developed enough for general use; as for any medical advance, we should wait for the evidence base that these procedures do improve quality of care and are cost effective.

Dennis Briley Consultant neurologist Stoke Mandeville Hospital NHS Trust, Aylesbury, Buckinghamshire HP21 8AI

1 Keogh BE, Dussek J, Watson D, Magee P, Wheatley D. Public confidence and cardiac surgical outcome. BMJ 1998 316:1759-60. (13 June.)

2 Blumenthal D. Part 1: quality of care-what is it? $N$ Engl J Med 1996;335:891-4.

3 Lanska D, Hartz AJ. Measurement of quality in health care. Neurology 1998;50:584-7.

4 Hinchey JA, Furlan AJ, Frank JI, Kay R, Misch D, Hill C. Is in-hospital stroke mortality an accurate measure of quality of care? Neurology 1998;50:619-25.

\section{Students must be taught more about ethics}

EDITOR-Taken with his letter in a previous issue, ${ }^{1}$ Johnson's editorial on self regulation is another nail in its coffin. ${ }^{2}$ His concern in "making self regulation credible" is to make it credible to doctors, not the public. In his letter he complained that the $B M$ ss use of a photograph of a bereaved Bristol parent sensationalised the issue. ${ }^{1}$ Maybe he saw only the model coffin in the picture. But doctors need to be reminded of the depth of sorrow and anger in that mother's eyes-the natural response when your child died unnecessarily.

It is the sorrow and anger caused by doctors to real, live people that self regulation must address. Patients with all their emotions have to be at the centre of self regulation-not some mechanically performed peer review. Johnson's editorial may read well in the corridors of medical politics, but it gives no comfort to patients trying to deal with the General Medical Council.

Last week I met a couple who had just been told that it would take the General Medical Council at least 12 months to decide whether to start disciplinary proceedings against a doctor. A year or more, that is, not from the time of their complaint but from delivery of a dossier that they had assembled at its request. The dossier consists of nearly 1000 pages of evidence supporting their complaint that one of their children died, and another was left severely brain damaged, as a result of being used without their consent in a research project.

Nor does the editorial give hope that the General Medical Council will better fulfil its statutory responsibility for medical education so that doctors will be trained not to abuse and misuse their patients. One possible approach is to teach students more of the humanities and, in particular, about ethics. Recognising this, the council instructed medical schools to teach medical ethics over a decade ago. Yet it has not withdrawn approval from those schools that still have no regular medical ethics teaching, one of which (the Middlesex/University College London) is right on its own doorstep. 
If leaders of the profession are incapable of recognising the centrality of patients and their experiences to self regulation, this extraordinary privilege will be taken away from us.

Richard Nicholson Editor

Bulletin of Medical Ethics, London N5 1LA

Bulletin_of_Medical_Ethics@compuserve.com

1 Johnson JN. Cover picture meant that BMJ had descended to level of tabloid newspapers. BMJ 1998;316:1831 (13 June.)

2 Johnson JN. Making self regulation credible. BMJ 1998; 316:1847-8. (20 June.)

\section{Bristol case highlights potential} weaknesses of Calman system

EDITOR-The Bristol case has implications for clinical governance, audit, management, and the provision of services, ${ }^{12}$ but what are the implications for specialist training? Having a rigorous training before acquiring independent contractor status is the ideal way to ensure high standards, as is acquiring self directed skills of learning and self criticism. Although this represents the traditional method of training in the United Kingdom and has generally led to a fairly high standard, some changes are now inevitable.

How does the Calman programme of specialist training fit these new demands? $\mathrm{In}$ many specialties the time available for training has been reduced. Additionally, on call rotas are being made less onerous as a result of European Union directives. Although training schemes are becoming better structured, these measures may lead to young specialists being well trained but less experienced than young specialists were previously. As a result, training posts have been set up for doctors who have gained a certificate of completion of specialist training. Another challenge will be for consultants to demonstrate their track record to patients and purchasers of care. How will a newly appointed specialist be able to do this without a sustained period under the proctorship of a more senior established colleague? Does this mean that "junior" consultants are inevitable?

The Bristol case highlights a further potential weakness of the Calman system in that some of the poor results were attributed to one surgeon having received most of his training under a senior colleague who himself later came under scrutiny. Previously, specialists spent time in two or three centres; in the Calman system a specialist's training might well be centred in one region. Therefore rotations are vital, and exchanges with other centres in different regions and travelling fellowships overseas will become important.

Close audit of both the trainees' and the trainers' case mix and outcomes is essential. This might best be supervised by the appropriate specialist society under the aegis of the royal colleges and postgraduate deans. This will particularly apply to complex and subspecialist work, for which the first direct exposure might previously have been as a newly appointed consultant. Supervised training has implications for time, resources, and throughput of patients. How will established consultants acquire new skills and techniques safely? Proctorships and sabbatical leave to other centres followed by close audit may be the only acceptable solution and yet have many consequences for the provision of services.

The training of specialists presents the medical profession with major challenges. Failure to meet these will jeopardise the whole ethos of self regulated postgraduate medical education.

Anjan K Banerjee Consultant surgeon Royal Halifax Infirmary, Halifax HX1 2YP

1 Klein R. Competence, professional self regulation, and the public interest. $B M J$ 1998;316:1740-2. (6 June.)

Treasure T. Lessons from the Bristol case. BMJ 1998:316: 1685-6. (6 June.)

3 Department of Health. Hospital Doctors - Training for the Department of Health. Hospital Doctors - Training for the
future report of the Working Group on Specialist Medical Training. London: DoH, 1993. (Calman report.)

\section{Private practice has similar problems}

Editor-I applaud the sentiments in Smith's editorial, but the focus seems to be on NHS medicine. ${ }^{1}$ An equal focus should be applied to private practice, where the motivation for inappropriate and excessive treatment is financial.

It was reported in BMA News Review that private practice could come under scrutiny by the Commons health select committee during the next parliamentary session, and David Hinchliffe MP was quoted as saying, "There is serious concern that certain operations, primarily in the private sector, are not performed by those sufficiently qualified to do so." I would suggest that unnecessary operations are a greater problem, some being performed by doctors who have had only basic training in the techniques while they were passing though a specialty.

The Bristol case has given every chairman of every medical advisory committee of every private hospital a great responsibility-that of "policing" his or her colleagues' activity in the private sector Moral support and advice are readily available from the General Medical Council, as I have recently found, and the medical director of the local NHS trust would also be an appropriate person to speak to.

What does one do if a colleague who is not an orthopaedic surgeon or hand surgeon operates on Dupytren's contractures, or a colleague who is not a plastic surgeon performs breast reductions, or a colleague who is not a gynaecologist inappropriately operates on genital prolapse? What do you do if a colleague always finds something to operate on no matter what the patient is referred with? And what do you say to the anaesthetist who always puts in a regional block as well as giving a general anaesthetic in order to bump up the fee? It astounds me that the medical insurance companies themselves have not policed these sorts of activities in order to reduce their own financial outgoings. All of these examples are observed every week by all of us who have our eyes open. Worse, they are obvious to our nursing and paramedical colleagues, who wonder why we are doing nothing to correct these anomalies.
Smith concluded his editorial with the spectre of micromanagement of doctors. It is therefore urgent that we put our own house in order and do not lose the impetus for change that the Bristol case has produced.

Beverley Webb Chairman of medical advisory committee

Pinehill Hospital, Hitchin, Hertfordshire SG4 9QZ

Smith R. All changed, changed utterly. BMJ 1998;316: 1917-8. (27 June.)

GP crisis wins Commons scrutiny. BMA News Review 1998 Jun 13:13.

\section{Formal mentoring might have helped}

EDITOR-One additional point that I think needs to be made after the Bristol case ${ }^{1}$ is how we are adequately to support doctors, particularly consultants. Senior doctors and particularly consultants (in all specialties) carry enormous loads; these are not only of basic clinical care and decision making but also managerial and educational roles; counselling roles for both patients, their families, and junior doctors; terminal and palliative care; and many other endless demands. In many other professions sensible arrangements have been made about mentorship and supervision of work in order to support people doing these difficult jobs-for example, in social work and psychology.

We need to help doctors by providing a much more structured form of mentorship or supervision to support them in the work they do. Otherwise we will continue to use our informal mentors of family and friends to share this load. If some formal mentoring or supervisory system had been in place for $\mathrm{Mr}$ Wisheart and colleagues, these doctors might have been able to express their anxieties and concerns about their surgical work; formal steps might then have been taken to address these issues. The current system clearly fails and does not allow such expression.

N Gainsborough Consultant physician Department of Medicine for the Elderly, Brighton General Hospital, Brighton BN2 3EW

1 Treasure T. Lessons from the Bristol case. BMJ 1998;316: 1685-6. (6 June.)

\section{Roles of GMC, royal colleges, and Department of Health remain unclear}

EDITOR-As Treasure and Klein point out, one the main questions arising from the Bristol inquiry is why so many warning signals went unheeded. ${ }^{12}$ In particular, although audit data from the United Kingdom cardiac surgery register seemed to raise questions about the performance of the Bristol unit, they were not acted on. In some ways this is not surprising. When audit was first introduced there was great reluctance to associate it with policies for professional accountability. One of the consequences was that royal colleges had no mechanisms in place to act on the findings of the national and regional audits they commissioned. Research on the audit programme of the Royal College of Physicians, undertaken in the early 1990s, found that audit had the characteristics of a research activity-owned by the individuals 
undertaking the work, disseminated by them through publication in journals, and presented at scientific meetings. ${ }^{3}$ At that time the Royal College of Physicians had no organisational mechanisms for dealing with the findings of audit.

The differing roles of the General Medical Council, the royal colleges, and the Department of Health in relation to the accountability of doctors remains unclear. The "rapid response" system being set up by the Royal College of Surgeons is clearly a step forward, but whether royal colleges will be able to set up organisational structures robust enough for rigorous peer review remains to be seen

Susan Kerrison Researcher

8 Ellesmere Road, London NW10 1JR

1 Treasure T. Lessons from the Bristol case. BMJ 1998;316: 1685-6. (6 July.)

2 Klein R. Competence, professional self regulation, and the public interest. BMJ 1998;316:1740-2. (6 July.)

3 Kerrison SH, Packwood T Buxton M. Review of supra hospital audit in medical specialities. Uxbridge: Health Economics Research Group, Brunel University: 1994.

Routine monitoring of mishaps would be valuable way of improving care

EDITOR-Smith states that cardiothoracic surgeons are well ahead of the pack in providing data on performance and that non-surgical specialties "are going to have to think hard and fast" about how to follow suit. ${ }^{1}$ Outcomes in medical specialties relate to diagnoses and treatments that are less clearly defined than operations. An accurate diagnosis based on agreed standard criteria is essential if valid comparisons are to be made. Comorbidity and other confounding factors must also be recorded. These constraints require both the diagnostic process and coding to be comprehensive and reliable, which they are not. Diagnoses may be uncertain and remain so, or provisional and clarified only after discharge.

Death is the easiest outcome to record; other adverse outcomes such as symptoms and disability are impossible to monitor routinely without a vast increase in resources. The cause of death is often uncertain and may be unrelated to the stated diagnosis. Necropsies are essential to determine both the cause of death and the accuracy of the original diagnosis, but rates of necropsy are low ${ }^{2}$ and, because of the shortage of pathologists, unlikely to increase. Death rates will be meaningless unless data on both diagnosis and cause of death are accurate. Moreover, few conditions have sufficiently high death rates for comparisons to be statistically valid. Collection of data for comparison between hospitals can thus have only a limited place. Improved internal audit and external peer review are far better options, and our royal college could have a strong role in both.

Routine monitoring of mishaps would be a valuable way of improving care. Many errors occur that are known only to the clinical staff involved unless a formal complaint is made or an incident form completed. Doctors may not be informed of their errors because of shifts, transfer of care to another team, or the problem being discovered after discharge. Mismanagement may be identified by other units in the same hospital or elsewhere. ${ }^{34}$ Adverse outcomes may be due to delays, ${ }^{3}$ problems with communication and filing, or lack of resources, especially of nurses and beds. Staff must be encouraged to report untoward events. The information can be used to identify repeating problems and areas for audit, to improve organisation, and to enhance education and audit. It would also strengthen the case for more resources.

R H Lloyd-Mostyn Consultant physician King's Mill Centre for Health Care Resources, Sutton in Ashfield, Nottinghamshire NH17 4JL

1 Smith R. All changed, changed utterly. BMJ 1998;316: 1917-8. (27 June)

2 Chana J, Rhys-Maitland R, Hon P, Scott P, Thomas C. Who asks permission for an autopsy? J R Coll Phys 1990;24:

3 Husband DJ. Malignant spinal cord compression: prospec tive study of delays in referral and treatment. $B M$ 1998;317:18-21. (4 July.)

4 McQuillan P, Pilkington S, Allan A, Taylor B, Short A, Morgan $\mathrm{G}$, et al. Confidential enquiry into quality of care before admission to intensive care. BMJ 1998;316:1853-8. (20 June.)

Doctors have surely forfeited privilege of self regulation

Editor-The General Medical Council's ruling concerning the paediatric heart surgeons in Bristol must raise the whole question of the propriety and effectiveness of self regulation by the medical profession. ${ }^{1}$ I would suggest that the signal failure by senior members of the profession to provide support for and ensure the health and welfare of so many of their junior hospital staff-often putting patients' safety at riskmust now result in forfeiture of the privilege of self regulation.

Michael Ashby-Miller Retired secretary, Nuffield

Provincial Hospitals Trust

28 Fitzwarren Gardens, London N19 3TP

1 Dyer C. Compensation claims expected to follow GMC's findings. $B M J$ 1998:316:1691. (6 June)

\section{Poor performers will need remedial training}

EDITOR-Who will help "poor performers" back into practice? This is a question that curiously, seems to be skirted. The General Medical Council is now empowered to assess a medical practitioner's performance after valid concerns have been expressed by patients, peers, other clinicians, or health management about a doctor's clinical practice. The advice is clear: a doctor should "act quickly to protect patients from risk." Removal from the medical register for not doing so is possible. The publicity about the Bristol case does not help matters. Although whistleblowing remains awkward, attitudes are changing: silent tolerance of poor clinical practice is no longer considered honourable.

Assessment, conducted by trained assessors, comprises interviews with the doctor, evidence from third parties (complainants and colleagues), and review of clinical records. A second phase will include objective tests of knowledge, attitudes, and skills. The assessors may recommend a period of remedial training. If the doctor is unable to improve or refuses to cooperate with a process of remedial training, suspension of his or her registration may occur. But the remedial process is not clear.

Although there is a recognition that the postgraduate system "is well placed to offer advice and practical support"s and an assumption that it will do $\mathrm{so}^{4}{ }^{4}$ there is no requirement to do so and no clear guidance. ${ }^{5}$ How realistic is this assumption? Providing remedial education is likely to be a highly specialised task but unfamiliar to most educationalists. Should they accept this role?

The need to provide remedial training will probably occur infrequently. But the low numbers envisaged mean that no one is likely to gain enough experience to provide acceptable remedial training in his or her field. The issues involved in mentoring, monitoring, and documentation are vague, and providing protected time for supervision has high opportunity costs. Poor performers are also likely to have complex problems, including conflicts within professional relationships.

The General Medical Council's firm lead on professional self regulation is welcome progress towards the setting of minimum standards. But identification and assessment are only the start. Remedial training has received little attention so far. Although some debate continues about funding, ${ }^{4}$ poor performers are widely expected to be responsible for the costs. Why should the taxpayer contribute twice to the establishment of a minimum level of professional competence? The most likely result of facing the performance procedures will probably be a swift move towards early retirement. So why bother setting up complex, expensive facilities for remedial training?

Glyn J Elwyn Senior lecturer in general practice Malcolm Lewis GMC performance assessor University of Wales College of Medicine, Cardiff CF4 4XN

elwynG@cf.ac.uk

1 General Medical Council. The duties of a doctor. London: GMC, 1997.

2 General Medical Council. The management of doctors with problems: referral of doctors to the GMC's fitness to practise procedures. London: GMC, 1997

3 NHS Executive. The management of doctors with problems: guidance on the role of the NHS in the GMC's performance procedures and the rehabilitation of doctors. Leeds: NHSE, 1997.

4 NHS Executive. GMC performance procedures: guidelines for the provision of advice and professional support to facilitate the rehabilitation of doctors. Leeds: NHSE, 1997

5 Rotherham G, Martin D, Joesburty H, Mathers N. Measures to assist GPs whose performance gives cause for concern Sheffield: School of Health and Related Research, 1997.

\section{Breaking down language barriers}

\section{Some ethnic groups may have problems} in getting as far as a consultation

EDITOR-Jones and Gill's timely editorial addressed the difficulties of general practitioners practising in a multilingual environment in the inner cities.

"A rapid access comprehensive telephone interpreting service in the NHS" may well help to make "equality of access more of a reality for some ethnic minority groups." 
However, to enable equality of access to services, the difficulties faced by some linguistic minority groups in getting as far as the consultation need also to be recognised. Important components of a system that will enable full access to services for linguistic minority groups include knowledge of the existence of services ${ }^{2 .}$ and the ability to contact them either by making an appointment in person or by telephone. ${ }^{4}$ For example, Vietnamese residents of Southwark and Lewisham had major gaps in their knowledge of the NHS. In particular, they did not know about out of hours arrangements for general practice. Those with limited skills in the English language even had difficulties booking appointments or requesting interpreters through the surgery. They were unable to contact general practitioners by telephone but were able to use open access surgeries or accident and emergency departments ( $\mathrm{C}$ Free et al, unpublished data). However, an interpreter is unlikely to be present at such unplanned attendances.

Further exploration of the use of telephone interpreting in consultations should be combined with a better understanding of how staff such as receptionists, who need to explain arrangements, might access an interpreter and how patients might obtain direct access to an interpreter who can help them negotiate the system.

Caroline Free Honorary research fellow

Department of General Practice and Primary Care, Weston Education Centre, King's College School of Medicine and Dentistry, London SE5 9PJ

1 Jones D, Gill P. Breaking down language barriers. BM 1998;316:1476. (16 May.)

2 Naish J. Intercultural consultations: investigating factor that deter non-English speaking women from attending their general practitioners for cervical screening. $B M J$ 1994;309:1126-9.

3 Smaje C. Health, "race" and ethnicity. Making sense of the evidence. London: King's Fund Institute, 1995:15.

4 Free C, McKee M. Meeting the needs of black and minority groups. $B M J$ J 1998:316:380.

\section{The public favours bilingual staff over interpreters}

EDITOR - In their editorial Jones and Gill commend accessible interpreting services including commercial telephone interpreting models, ${ }^{1}$ but they approach the problem from the perspective of NHS providers rather than the public. For example, people from ethnic minority groups in emotional distress prefer bilingual workers to interpreters. ${ }^{2}$ Health professionals rarely consider the pitfalls of using interpreters. ${ }^{3}$

Numbers of visits to general practitioner by Punjabi Asian and white English patients according to type of practice

\begin{tabular}{|c|c|c|c|c|c|}
\hline \multirow[b]{2}{*}{ Practice } & \multirow[b]{2}{*}{ Practice type } & \multicolumn{2}{|c|}{ Unweighted attendance data } & \multicolumn{2}{|c|}{ Culture (Punjabi $v$ English) } \\
\hline & & Punjabi & English & $\begin{array}{l}\text { Weighted odds ratio } \\
\qquad(95 \% \mathrm{Cl})\end{array}$ & $P$ value \\
\hline $\bar{A}$ & 2 partners, practice nurse & 38 & 38 & 1 & \\
\hline B & $\begin{array}{l}2 \text { partner health centre, visiting } \\
\text { consultants, nurses, counsellor }\end{array}$ & 140 & 49 & 2.59 (1.40 to 4.77$)$ & 0.002 \\
\hline $\bar{c}$ & $\begin{array}{l}3 \text { partner health centre, } \\
\text { multidisciplinary team, } \\
\text { visiting consultants }\end{array}$ & 13 & 88 & 0.14 (0.06 to 0.31$)$ & $<0.001$ \\
\hline $\mathrm{D}$ & 1 general practitioner, practice nurse & 17 & 3 & 6. 76 (1.80 to 25.43$)$ & 0.004 \\
\hline $\mathrm{E}$ & 1-2 partners, practice nurse & 0 & 11 & Dropped from & \\
\hline
\end{tabular}

I recently recruited 210 Punjabi Asian and 188 white English patients to the second phase of a prevalence survey based in five general practices in an electoral ward practices were in close proximity. Data were analysed using weighted logistic regression using the complete data from the second stage interviews of 383 patients (208 Punjabi Asians and 185 white Londoners). All of the general practitioners were of Asian origin and spoke at least two Asian languages; a general practitioner who spoke Punjabi was found in all but one practice (A in table). I found that more Punjabi Asian attenders visited their general practitioner when the receptionists were bilingual (practices $B$ and $\mathrm{D}$ in the table).

Although interpreters are commonly seen as a ubiquitous solution to overcome barriers of healthcare provision for a multilingual population, bilingual staff seem to be favoured by the public and improve access to general practitioners. The presence of bilingual staff may also avoid the pitfalls of using interpreters.

Kamaldeep Bhui Wellcome training fellow Institute of Psychiatry, London SE5 8QF

1 Jones D, Gill P. Breaking down language barriers. $B M$ J 1998:316:1476. (16 May.)

2 NHS Executive. Black mental health: a dialogue for change. Heywood, Lancashire: Health Publications Unit, 1994 3 Westermeyer J. Working with an interpreter in psychiatric assessments. J Nerv Mental Dis 1990;178:745-9.

\section{Don't forget deaf people}

EDITOR-Jones and Gill did not mention interpreting services for people whose first language is British sign language in their editorial. ${ }^{1}$ Obviously, telephone translation services would not work unless there was simultaneous video transmission.

Another problem is the awareness of and use of available services by health professionals. In a survey one of us (SM) found that $62 \%$ of general practices and $27 \%$ of hospital consultants were not aware that such services exist. ${ }^{2}$ In addition, $82 \%$ of practices thought that it was acceptable to use family or friends to interpret consultations.

Given that around 12000 profoundly deaf and 43500 severely deaf people live in the United Kingdom, this group has to be considered when providing "accessible interpeting services for all."'

John Irwin Consultant audiological physician Suzanne Martin Fourth year medical student Ninewells Hospital, Dundee DD1 9SY of a London borough. Therefore all of the
1 Jones D, Gill P. Breaking down language barriers. BMJ 1998;316:1476. (16 May.)

2 Martin S. British sign language interpreting services for the deaf in Dundee [fourth year assignment]. Dundee: University of Dundee, 1998.

\section{Sign here, please}

EDITOR-"The NHS needs to provide accessible interpreting services for all" is the subheading of Jones and Gill's recent editorial, but they do not mention deaf people or people who are hard of hearing. At least 60000 people in the United Kingdom use British sign language as their first or preferred language, and others communicate through other visual means. ${ }^{2}$

Many of the points made by Jones and Gill in relation to the use of interpreters for ethnic minority groups also apply to deaf people, but a rapid access telephone interpreting service is not a solution. Other forms of technology could be used for visual languages, but the conventional telephone is not an option because the deaf person and the interpreter need to see each other.

Failing to ensure that deaf people and people who are hard of hearing have full access to health services is not only poor practice in terms of equity but could also lead to health providers having action taken against them under the Disability Discrimination Act 1995 when it becomes fully implemented within the next few years. In relation to this act the Department of Health has held two conferences about disabled people in hospital; these included contributions from deaf people, and the proceedings have been published as advice on good practice. ${ }^{3}$

Deaf people and people who are hard of hearing face many barriers in using health services. For example, the reliance of such services on the use of voice only telephones means that tasks such as making or changing an appointment, gaining access to health information, and inquiring about a relative's health are unnecessarily difficult. Few health agencies have text phones, although they are comparatively cheap and easy to use. ${ }^{3}$

The Royal College of Physicians has recently published a charter for and guidelines about disabled people using hospitals; this includes guidelines on making services accessible for deaf people and people who are hard of hearing, and these would be useful for primary care and other health services.

Joyce Carter Consultant in public health medicine Liverpool Health Authority, Liverpool L3 6AI

Kathie Hare-Cockburn Fieldworker in advocac North Regional Deaf Association, Merseyside Society for Deaf People, Liverpool L13 0DJ

1 Jones D, Gill P. Breaking down language barriers. BMJ 1998;316:1476. (16 May.)

2 Social Services Inspectorate. A service on the edge. Inspection of services for deaf and hard of hearing people. London: Department of Health, 1997.

3 Health Services Directorate. Patients disabled? The care of disabled people in hospital. Conference report. Leeds: NHS Executive, 1997.

4 Royal College of Physicians. Disabled people using hospitals-a charter and guidelines. London: RCP, 1998. 


\section{Pressure on doctors to prescribe need measuring directly}

EDITOR-Ramsden et al found that there was no relation between general practitioners' confidence in the pharmacological efficacy of their prescriptions and the patients' expectations for prescriptions. ${ }^{1}$ They concluded that doctors are not pressurised into giving prescriptions they do not believe are of benefit. This contradicts our results, which were based on a survey of consultations carried out in four general practices in south London. $^{2}$

Whereas Ramsden et al used the patients' expectations as a proxy for doctors feeling pressurised, we measured both of these variables directly. We found a significant relation between patients' hopes for prescriptions and doctors feeling pressurised, doctors being more likely to feel pressurised if the patients hoped for prescriptions $(46 / 266(17.3 \%)$ v $2 / 154 \quad(1.3 \%)$, $\left.\chi^{2}=24.6, \mathrm{df}=1, \mathrm{P}<0.001\right)$. However, for over half of the consultations patient expectations did not identify pressurised doctors, mainly because of the large number of cases for which the patient hoped to receive a prescription but the doctor did not feel under pressure $(52 \%(220 / 420))$. On this evidence Ramsden et al may have overestimated the number of doctors who feel under pressure. To draw conclusions about whether doctors feel pressured to write prescriptions you have to ask directly.

When consultations in which a repeat prescription was issued were excluded we still found that the odds of prescriptions being medically indicated were significantly higher in consultations in which doctors did not feel pressurised than in those in which they did (odds ratio 7.2 (95\% confidence interval 3.4 to 15.6)). Explanation of these findings requires careful investigation.

O C Ukoumunne Medical statistician Department of Medical Statistics and Evaluation, Imperial College School of Medicine, Hammersmith Hospital, London W12 0NN o.ukoumunne@rpms.ac.uk, o.ukoumunne@ic.ac.uk

N Britten Senior lecturer in medical sociology Department of General Practice, United Medical and Dental Schools of Guy's and St Thomas's Hospitals, London SE11 6SP

1 Ramsden JD, Quinn FR, Witham M. Doctors are not pressured into giving prescriptions. BMJ 1998;316:938-9. (21 March.)

2 Britten N, Ukoumunne O. The influence of patients' hopes of receiving a prescription on doctors' perceptions and the decision to prescribe: a questionnaire survey. BMJ 1997 315:1506-10. (6 December.)

\section{Safety of patients participating in drug trials}

\section{Use of placebo in trials of drugs for mental illness should be debated}

EDITOR-Several advertisements have recently been placed in the national and local press by a private agency, requesting volunteers with manic depression to join a drug trial. This drug trial requires participants to stop all current drug treatment, albeit under psychiatric supervision. They are then randomised to one of three groups, receiving treatment with lithium, lamotrigine (at one of three doses), or placebo for one year.

This poses three ethical problems. Firstly, advertising publicly for volunteers with serious mental illness is a dubious practice. Secondly, there is evidence that stopping lithium, as required by the trial, results in both relapse and a more severe pattern of illness. ${ }^{12}$ Thirdly, most participants in the trial will not be treated with an established mood stabilising drug. This would be unacceptable in trials for drugs to treat participants with life threatening infections or cancer. It is no more acceptable for severe mental illness.

The use of placebo in trials of drugs for mental illness should be debated, and so should the issue of informed consent, rather than taken for granted as it is at present. Moreover, I would like to see Glaxo Wellcome accept responsibility for all episodes of mental illness that might have been prevented if its trial of lamotrigine ( $£ 60$ (\$96) a month and two years left on its patent) was being run more sensitively.

Elizabeth Armstrong General practitioner Hyde Park Gate, London SW7 5DZ

1 Baldessarini RJ, Tondo L, Faedda GL, Suppes TR, Floris G, Rudas N. Effects of the rate of discontinuing lithium maintenance treatment in bipolar disorders. J Clin Psychiatr tenance treatm

2 Post R, Weiss S. Kindling and stress sensitization. In: Young Post R, Weiss S. Kindling and stress sensitization. In: Young
LT, Joffe RT, eds. Bipolar disorder. Biological models and their clinical application. New York: Marcel Dekker, 1997:120.

\section{Glaxo's reply}

EDITOR-Armstrong raises issues that are similar to those that Glaxo Wellcome takes into consideration when it designs and implements its clinical trial programmes. The safety of patients is our top priority. Bipolar disorder is difficult to diagnose and treat. Sufficient numbers of patients must be recruited for questions of absolute and relative efficacy and safety to be answered in studies that evaluate new treatments. Advertising for patients is an accepted method of improving recruitment in many areas of treatment, and these advertisements must be approved by an ethics committee. In addition, patients are rigorously screened over the telephone to assess their suitability before they attend the study site.

All patients taking part in a study give their full informed consent before they enter the screening process. We take this procedure seriously, giving a full explanation of the trial design and objectives, ample opportunity for questions, and plenty of time for patients to consult their current psychiatrist, general practitioner, family, and friends. Information from the psychiatrist currently treating a patient is also sought before that patient enters the study. Patients are at liberty to withdraw consent at any time. They enter the study during an uncontrolled episode of mania or depression. They are then given lamotrigine, and when their condition has stabilised and their current episode resolving, lithium is withdrawn over not less than three weeks. Those not responding to treatment with lamotrigine continue to take lithium and do not enter the randomised phase of the trial. Armstrong suggests that stopping lithium results in a more severe pattern of illness; but slow withdrawal (over more than two weeks) is less likely to provoke relapse and is recommended in the evaluation of new interventions.

The use of placebo in these studies is a regulatory requirement for proof of efficacy; it also means that studies can be smaller and shorter. This exposes fewer patients to an unproven intervention and gives an answer about efficacy more quickly. If that answer is positive patients should be able to benefit early. If it is negative, fewer patients will be exposed to ineffective treatment. Glaxo Wellcome, together with those independent experts who contributed to the trial design, puts the safety of patients as its top priority in investigating much needed alternative treatment for bipolar disorder. While Armstrong is correct in her assertion that lamotrigine is not a currently established mood stabiliser, these studies, based on positive preliminary evidence, will provide an indication of its place in treatment.

Stuart Dollow Head of medical advisory group Glaxo Wellcome UK, Uxbridge, Middlesex UB11 1BT

1 Baldessarini RJ, Tondo L, Floris G, Rudas N. Reduced morbidity after gradual discontinuation of lithium treatment for bipolar I and II disorders: a replication study. Am J Psychiatry 1997;154:551-3.

\section{If devolved facilities are used, processes may be streamlined}

EDitoR-New healthcare technologies are often expensive. Maximising their use may become an objective in its own right, with the equipment centralised and protected by a host department-the radiology department in the case of magnetic resonance imaging, for example. The convenience of staff and patients takes second place.

The legacy of early, appropriate centralisation may persist long after the economic and technical arguments have lapsed as prices come down and reliability improves. The process of obtaining a plain chest $x$ ray film through a centralised department may involve up to 10 members of staff, use two hours of their time, and take patients off the ward for several hours. ${ }^{1}$ If devolved facilities are used the process may be streamlined to involve just two members of staff-the requesting doctor and a radiographer ${ }^{2}$ (although this does not include formal reporting of a film by a radiologist, which is often helpful though less frequently available out of hours).

It is not surprising that the point of care pathology testing that Kendall et al describe produces swifter results than when samples are sent to the hospital laboratory and that management decisions may therefore be made sooner. ${ }^{3}$ If the doctors who took the blood samples had also put them through the point of care analysers, even faster results could have been obtained, with less 
chance of the process failing due, for instance, to mislaid specimens or results.

Given the complexity of a typical modern (and busy) accident and emergency department, it would have been surprising if the swifter availability of results in itself greatly improved patient flows. Pathology testing is only one aspect of patients' management. But by ensuring that delays do not occur because test results are absent, whether awaited or lost, Kendall et al's department has built a platform from which to redesign its other processes to improve the experience of both patients and staff. They have the opportunity to reduce the time that patients spend in the department and perhaps even improve clinical outcomes.

Tim Heymann Consultant physician Kingston Hospital, Kingston upon Thames, Surrey KT2 7QB

1 Black A, Garside P. Patient focused care: Health Service Journal health management guide. [Distributed free with Health health management guide. [D

Heymann TD, Culling W. Ward based X-ray facilities can improve services.J R Coll Phys Lond 1996;30:145-9.

3 Kendall J, Reeves B, Clancy M. Point of care testing: randomised controlled trial of clinical outcome. $B M J$ 1998;316:1052-7.

\section{Use of the READER method of critical appraisal in general practice}

\section{Study did not properly answer the questions it posed}

EDITOR-Critical reading is becoming increasingly important in an era of abundance of information. MacAuley et al have undertaken an admirable job by studying one method of critical appraisal of medical literature. ${ }^{1}$ However, I do not think that their study properly answered the questions that it posed.

The apparent strength of this READER method is its simplicity. The method has several drawbacks, however. Items are not independent. When relevance is absent in the eye of the reader, little energy will be invested in assessing the methodological qualities of the paper.

Serious problems arise in the "discriminative" component of the checklist. Here we find a strange mix of design type and design quality. A randomised, double blind trial with serious flaws may be far less informative than a good descriptive study. In the READER method, however, the first will score 7 or 8 points, whereas descriptive studies cannot score more than 4 points. The impression that this list has ordinal or even interval scale properties, as given by the presentation of means, is not justified.

A major problem of the study is the choice of the outcome measure. The outcome measure we really should be curious about is the discriminatory power of the reader using this method. The choice of papers, all from the "General practice" section of the $B M J$, does not allow conclusions about the readers' ability to discrimi- nate according to relevance for general practice, which is one of the four items of the READER checklist.

Furthermore, numerical scores on three papers do not give us much information about the ability of the reader to pick the relevant and applicable conclusions from these papers.

Johannes C van der Wouden Research coordinator Department of General Practice, Room Fe319,

Erasmus University Rotterdam, PO Box 1738, 3000 DR Rotterdam, Netherlands

(vanderwouden@hag.fgg.eur.nl)

1 MacAuley D, McCrum E, Brown C. Randomised controlled trial of the READER method of critical appraisal in general practice. BMJ 1998;316:1134-7. (11 April.)

\section{Author's reply}

EDITOR-Van der Wouden highlights some drawbacks of the READER model, and I agree that it is not perfect. A simple model cannot address all the complexities of critical reading, and the discrimination component cannot address every variation in study quality. Such safeguards would make the model unwieldy, and its strength is in its simplicity. The issue of relevance is important, and the original description of the model suggests that steps in the READER model should be sequential so that if a study is not relevant there is no point in continuing. The discriminative component is an attempt to integrate quality and study hierarchy, an almost impossible task, and I welcome suggestions on ways to weight this scoring. The purpose of the study was to test a model that could help general practitioners to decide which papers to read and which to discard. I too was concerned about the discriminative power of the model in this study-where papers in the GP section of the $B M J$ would be more likely to be relevant, educational, and of high quality-but the model did detect differences.

I argue therefore that this study did answer the question it posed, but I agree that it would be more important to detect whether general practitioners picked up the salient points of the study. The ultimate outcome measure would be to identify change in behaviour. But first, they must decide what to read-hence the READER model.

Domhnall MacAuley General practitioner Hillhead Family Practice, 33 Stewarts Road, Belfast BT11 9SZ

\section{Living wills might make patients at risk of death by starvation and dehydration}

EDITOR-MORI's survey on living wills obfuscated the critical distinction between a person refusing treatment for a medical condition that he or she is experiencing and understands and that person refusing treatment for some future condition of which he or she has no knowledge. ${ }^{1}$ The survey also referred to the legal right of a competent patient to refuse treatment, implying that legally binding living wills are a logical extension of that right.
It is deeply unsatisfactory that the survey should refer to the treatment of competent patients-which is not the issue here-while failing to state that at common law doctors are free to act in the best interests of patients who are currently incapable of consenting to treatment. As I understand it, the judgment in Re C, ${ }^{2}$ to which Dyer refers, safeguarded C's continuing refusal of amputation; this is a different situation from a "living will" coming into effect when a patient becomes incapacitated.

Furthermore, would many respondents to the survey have realised that refusing medical treatment could include refusing the provision of food and water by tube, so that they might be instructing doctors to bring about death by starvation and dehydration? The Law Commission's proposals for the mental incapacity bill being promoted by the government would allow living wills to have this effect. ${ }^{3}$ Unless the government gives a commitment to excluding such practices from any legislation, its protestations that it is opposed to euthanasia are disingenuous. It is perplexing that a journalist of Dyer's standing should repeat the government's line so uncritically.

Ann Widdecombe Member of parliament House of Commons, London SW1A 0AA

1 Dyer C. UK public calls for legislation over living wills. BMJ 1998:316:959. (28 March.)

2 Re C (adult refusal of treatment) [1994] WLR 290.

3 Gadd E. Changing the law on decision making for mentally incapacitated adults. BMJ 1997;316:90. (10 January.)

\section{Deaths outside hospital from acute coronary events}

\section{Early access to defibrillation is a key to survival}

EDITOR-We wish to comment on some of the strategies suggested by Norris et al to reduce mortality from acute coronary attacks. ${ }^{1}$ Recently we reviewed outcomes for all cardiac arrests in adults presenting to the emergency department at the Norfolk and Norwich Hospital during 1991 and 1996. The region served by this hospital is semirural, with a single tier response ambulance service. Between 1991 and 1996 several changes were made to the organisation and delivery of prehospital care. Foremost was the amalgamation of the three ambulance services covering East Anglia. The proportion of calls answered by a paramedic crew also changed, increasing from $70 \%$ to $100 \%$. Ninety five per cent of calls were answered within 16 minutes in 1991 and within 22 minutes in 1996. Despite these changes there was no significant difference in outcome. Fifteen out of 113 victims survived to discharge in 1991 compared with 11 out of 147 in 1996.

Early access to defibrillation is a key to survival. The NHS target of an ambulance response within 8 minutes for $90 \%$ of calls ${ }^{2}$ is probably too long. None the less in semirural regions such as Norfolk, early access would be difficult to achieve without resorting to some of the options mentioned by Norris et al, such 
as a dual response system. Elsewhere police and fire service staff have been trained in the use of automated external defibrillators and included in a rapid response tier. ${ }^{3}$ For an urban area such as Norwich, the fire service has a statutory obligation to attend to all fires within 5 minutes, ${ }^{4}$ and if included in such a rapid response system may help to reduce significantly the delay before defibrillation.

Norris et al suggested intensified citizen training in cardiopulmonary resuscitation. In our series, among the cardiac arrests witnessed by members of the public, the proportion receiving immediate basic life support was significantly smaller in 1996 than in $1991(34 \%(27 / 79) v 67 \%(33 / 49))$. This suggests increased hesitance on the part of the public to initiate resuscitation attempts. Perhaps public education campaigns should focus on this issue. Finally, we agree with Norris et al on the importance of educating the public to interpret premonitory signs of coronary events and to summon the emergency services without delay. Most of our survivors (10 in 1991, 9 in 1996) called for help early, had their cardiac arrest in an ambulance or doctor's surgery, and were defibrillated promptly.

A Absalom Research fellow

University Department of Anaesthesia, Glasgow

Royal Infirmary, Glasgow G31 2ER

P Bradley Senior house officer

Department of Anaesthesia, Norfolk and Norwich Hospital, Brunswick Road, Norwich NR1 3SR

J Soar Specialist registrar

Sir Humphry Davy Department of Anaesthesia, Bristol Royal Infirmary, Bristol BS6 8HW

1 Norris RM on behalf of the United Kingdom Heart Attack Study Collaborative Group. Fatality outside hospital from acute coronary events in three British health districts, 1994-5. BMJ 1998;316:1065-70. (4 April.)

2 NHS Executive. Review of ambulance performance standards. Final report of steering group. London: NHSE, 1996.

3 White RD, Asplin BR, Bugliosi TF, Hankins DG. High rate of discharge survival rate after out-of-hospital ventricular fibrillation with rapid defibrillation by police and paramedics. Ann Emerg Med 1996;28:480-5.

4 Central Fire Brige Advisory Counil The report of the join committee om standards of fre cover. London: HMSO, 1985.

Community training in resuscitation and other therapies is needed

EDITOR-Norris et al and Ruston et al point to the importance of behaviour outside hospital in the prevention of sudden death. ${ }^{2}$ We studied all cases of sudden death in people aged under 70 years that was attributed to ischaemic heart disease in a population of 330000 over a period of nine months. Our findings support and strengthen the case for community training in resuscitation.

Qualitative and quantitative data were collected from proxies for cases (generally, the nearest relative) whenever these could be identified. Sixty proxies were interviewed; these indicated that in most (52) cases the collapse had been witnessed, and hence basic life support would have been appropriate while professional help was awaited. This help took a median of 15 minutes to arrive, which is too long to be associated with a successful outcome in the absence of life support. ${ }^{3}$

Only 8 (14\%) people had warning symptoms of any sort preceding their collapse, which fits findings of Norris et al that just $5 \%$ of people experienced cardiac arrest in the presence of a paramedical crew equipped with a defibrillator. A policy of calling an ambulance after 15 minutes of chest pain will be unlikely to make a large impact in preventing sudden death, but would incur a considerable workload. The cost effectiveness of such a policy needs further investigation.

About half of the cases in our small series had a previous diagnosis of coronary heart disease. Secondary prevention of coronary heart disease with drug treatment and lifestyle change is of established effectiveness and cost effectiveness. A combination of training in resuscitation and other therapies might be even more productive.

Alison Round Consultant in public health medicine North and East Devon Health Authority, Exeter EX1 1PQ

Maurice Backett Professor emeritus in community health

53 Fore Street, Totnes, Devon TQ9 5NJ

Claire Hunter Research associate

Andrew Marshall Consultant cardiologist

Derriford Hospital, Plymouth PL6 8HD

1 Norris RM on behalf of the United Kingdom Heart Attack Study Collaborative Group. Fatality outside hospital from Study Collaborative Group. Fatality outside hospital from acute coronary events in three British

2 Ruston A, Clayton J, Calnan M. Patients' action during Ruston A, Clayton J, Calnan M. Patients' action during
their cardiac event: qualitative study exploring differences and modifiable factors. BMJ 1998:316:1060-5. (4 April.) and modifiable factors. BMJ 1998;316:1060-5. (4 April.)

Cummins RO, Ornato JP, Thies WH, Pepe PE, Billi PE, Seidel J, et al. Advanced Life Support Committee and Emergency Cardiac Care Committtee of the American Heart Association: improving survival from sudden cardiac arrest: the chain of survival concept. Circulation 1991;83:1832-47.

\section{Drug treatments for asthma may cause erosive tooth damage}

EDITOR-The prevalence of asthma in children is high, and prophylactic and symptomatic drug treatments for asthma are widely advertised in medical journals. We would like to draw attention to a potential problem that may arise with the dentition when some of these drugs are taken. A large study on the various risk factors associated with acid erosion of teeth in children found that, compared with a control group, the affected children included a high proportion with asthma; another study of children with asthma found an increased prevalence of dental erosion.

One possible explanation for the acid erosion of the teeth of people with asthma is that they have an increased incidence of gastro-oesophageal reflux, ${ }^{2}$ a known cause of dental erosion. The frequent use of oral drugs may also be implicated.

A further investigation of the drug treatments used by children with asthma examined the $\mathrm{pH}$ of the drugs in both the powdered and aerosol forms of delivery in vitro (table). The $\mathrm{pH}$ of the powdered and aerosol forms differed significantly $(\mathrm{P}<0.001)$, with almost all drugs having a $\mathrm{pH}$ of $<5.5$ in the powdered form. Tooth substance begins to dissolve at $\mathrm{pH} 5.5$. $^{3}$ When used several times a day these drugs may contribute to the dissolution of enamel surfaces of the teeth that they contact.

As increasing numbers of children are using the powdered form of drugs, doctors should advise children to rinse their mouths with water directly after taking the drugs. The use of a spacer device may also be of benefit in delivering the dose to the back of the mouth. Children should also be encouraged to clean their teeth thoroughly at least twice a day with a fluoride toothpaste. This would help to prevent dental erosion, which may cause considerable sensitivity and is both costly and time consuming to treat. This letter is an early warning of the potential problem of tooth erosion associated with drugs used to control asthma, particularly in children. We intend to publish a full report of the investigation.

This research was funded with a Wellcome research training fellowship.

Elizabeth A O'Sullivan Senior registrar

Martin E J Curzon Professor

Department of Paediatric Dentistry, Leeds Dental Institute, Leeds LS2 9LU

1 McDeera E, Pollard M, Curzon M. The dental status of British asthmatic school children. Pediatr Dent (in press).

2 Wilson N, Charette L, Thompson A, Silverman M. Gastrooesophageal reflux and childhood asthma: the acid test. Thorax 1985;40:592-7.

3 Stephan R Intra-oral hydrogen-ion concentrations associated with dental caries activity. J Dent Res 1944;23:257-66.

$\mathrm{pH}$ of various drugs to treat asthma

\begin{tabular}{|c|c|c|c|c|}
\hline Generic name of drug & Proprietary name & Dose $(\mu g)$ & Delivery & $\mathrm{pH}^{*}$ \\
\hline \multirow{2}{*}{ Beclomethasone diproprionate } & \multirow{2}{*}{ Becotide } & 200 & Powder & 4.76 \\
\hline & & 200 & Aerosol & 7.76 \\
\hline \multirow{2}{*}{ Fluticasone } & \multirow{2}{*}{ Flixotide } & 100 & Powder & 4.76 \\
\hline & & 125 & Aerosol & 7.73 \\
\hline \multirow{2}{*}{ Budesonide } & \multirow{2}{*}{ Pulmicort } & 400 & Powder & 6.47 \\
\hline & & 200 & Aerosol & 8.34 \\
\hline \multirow{2}{*}{ Salbutamol } & \multirow{2}{*}{ Ventolin } & 200 & Powder & 5.94 \\
\hline & & 100 & Aerosol & 9.30 \\
\hline \multirow{2}{*}{ Salmeterol } & \multirow{2}{*}{ Serevent } & 50 & Powder & 5.49 \\
\hline & & 25 & Aerosol & 7.24 \\
\hline \multirow{2}{*}{ Terbutaline sulphate } & \multirow{2}{*}{ Bricanyl } & 500 & Powder & 4.31 \\
\hline & & 250 & Aerosol & 7.03 \\
\hline Ipratropium bromide & Atrovent & 20 & Aerosol & 7.88 \\
\hline \multirow{2}{*}{ Sodium cromoglycate } & Intal & 20 & Powder & 5.54 \\
\hline & Cromogen & 5 & Aerosol & 7.34 \\
\hline
\end{tabular}

${ }^{\star} \mathrm{P}<0.001$ by paired $t$ test. 